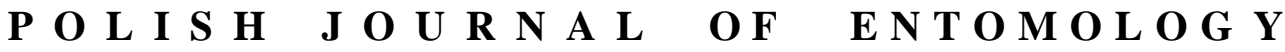

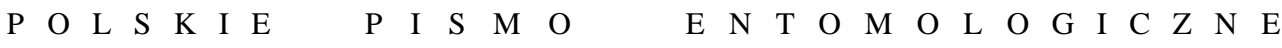

VOL. 84: 361-370

Lublin

30 December 2015

DOI: $10.1515 /$ pjen-2015-0031

\section{Capitophorus wojciechowskii - a new aphid species from Iran (Hemiptera: Aphididae: Aphidinae: Macrosiphini)*}

\author{
KARINA WIECZOREK, MARIUSZ KANTURSKI \\ Department of Zoology, Faculty of Biology and Environmental Protection, University \\ of Silesia, Bankowa 9, 40-007 Katowice, Poland, \\ e-mails: karina.wieczorek@us.edu.pl,mkanturski@us.edu.pl
}

\begin{abstract}
A new aphid species - Capitophorus wojciechowskii sp. n. - from northern Iran, associated with Hippophae rhamnoides and Hippophae sp., belonging to the tribe Macrosiphini (Hemiptera: Aphididae) is described. The fundatrix, apterous viviparous female, oviparous female and apterous male are described and illustrated. Similarities and differences with other Capitophorus species living on Elaeagnaceae are discussed. A key to Elaeagnaceae feeding aphids from the genus Capitophorus is also provided.
\end{abstract}

KEY WORDS: aphids, Elaeagnaceae, Hippophae, new species.

\section{INTRODUCTION}

The genus Capitophorus VAN DER GOOT, 1913, belonging to the tribe Macrosiphini, comprises about 30 described Nearctic, Palaearctic and Oriental species (BLACKMAN \& EASTOP 2015). Aphids from this genus are characterized by a slender, very pale, almost translucent body and long legs. Apterous viviparous females of almost all species also have capitate, mushroom-shaped or fan-shaped setae of variable length on dorsum, antennae and legs.

\footnotetext{
* The paper is dedicated to Prof. Wacław WOJCIECHOWSKI in recognition of his great contribution to the taxonomy and faunistics of Hemiptera.
} 
Representatives of this genus are associated with trees, shrubs or herbaceous plants from the subfamilies Elaeagnaceae, Polygonaceae and Asteraceae and can be either monoecious or host-alternating (BLACKMAN 2010). Elaeagnaceae trees and shrubs are host plants for all 11 species: 7 on Elaeagnus spp. and 9 on Hippophae spp., where the aphids live on the underside of the leaf.

During work in the Aphididae collection of the Muséum national d'Histoire naturelle, Paris (MNHN), specimens of a new species of the genus Capitophorus were found: the description is given in this paper.

\section{Acknowledgements}

The authors would like to express their gratitude to the late Georges REMAUDIÈRE, Danièle Matile-Ferrero, Thierry Bourgoin and Laurent FaUvre (MNHN, Paris, France), Diana M. PERCY and Paul A. BROWN (BMNH, London, UK) for their kind help and for providing the opportunity to examine the material. Special thanks go to Lukasz JUNKIERT, University of Silesia, Katowice, for preparing the drawings. We are very grateful to anonymous Reviewers and the Editor for all valuable suggestions that have improved the manuscript.

\section{MATERIAL AND METHODS}

The following abbreviations (in the descriptions and table) are used (partly following BLACKMAN \& EASTOP 1994): BL - body length; MW - maximum width; HW - head width across compound eyes; ANT - antennae or their lengths; ANT I, II, III, IV, V, VI antennal segments I, II, III, IV, V, VI or their lengths; B ASE - basal part of last antennal segment or its length; PT - terminal process of last antennal segment or its length; ROSTR - rostrum length; ARS - apical segment of rostrum or its length; III FEMUR hind femur length; III TIBIA - hind tibia length; HT I - first segment of hind tarsus or its length, HT II - second segment of hind tarsus or its length.

The specimens were examined using a Nikon Ni-U light microscope. Drawings were made with the aid of a camera lucida. Measurements are given in $\mathrm{mm}$. 


\section{SYSTEMATICS}

\section{Capitophorus wojciechowskii sp. n.}

(Figs 1-2)

\section{Material}

Holotype. Iran, Gach-i-Sar, 2000 m, one apterous viviparous female, Hippophae, 14 X 1955, ReMAUdiÈRE, MNHN (EH) 22598.

Paratypes. Three slides with one oviparous female MNHN (EH) 22596, three oviparous females 22607, four males 22603, the same data as holotype. Four slides with one apterous viviparous and one oviparous females MNHN (EH) 22595, one apterous viviparous and one oviparous females 22599, two males 22604, two oviparous females 22606, Iran, Facham, 1900 m, Hippophae rhamnoides, 23 XI 1962, REMAUDIÈRE. One slide with four fundatrices MNHN (EH) 22600, Iran, Asara, 850 m, Hippophae rhamnoides, 27 IV 1963, REMAUDIÈRE.

The type material is deposited in the Museum national d'Histoire naturelle, Paris, France (MNHN). Two paratypes MNHN (EH) 22595, 22604 will also be deposited in the aphid collection of the Department of Zoology, University of Silesia, Katowice, Poland (UŚ).

\section{Etymology}

The new species is named in honour of Professor Wackaw WOJCIECHOWSKI, the eminent Polish aphidologist, on the occasion of his $70^{\text {th }}$ birthday and the $50^{\text {th }}$ anniversary of his scientific work.

\section{Diagnosis}

Morphologically the new species is related to C. xanthii (OESTLUND, 1886) and C. shepherdiae GILLETTE \& BRAGG, 1916 by having submarginal setae and duplicated marginal ones. Also C. xanthii and C. shepherdiae are characterized by very short dorsal setae with wide, fan-shaped apices, and they are shorter than their width. The two species also have short, club-shaped external setae on the hind tibiae as well as a more or less rugose cuticle at least in the spinal area of the dorsum. C. wojciechowskii sp. n. differs in the evidently long dorsal setae with mushroom-shaped apices, at least three times longer than wide. The external setae on the hind tibiae are long and of the same shape, and the cuticle is smooth (in apterous viviparous females). 

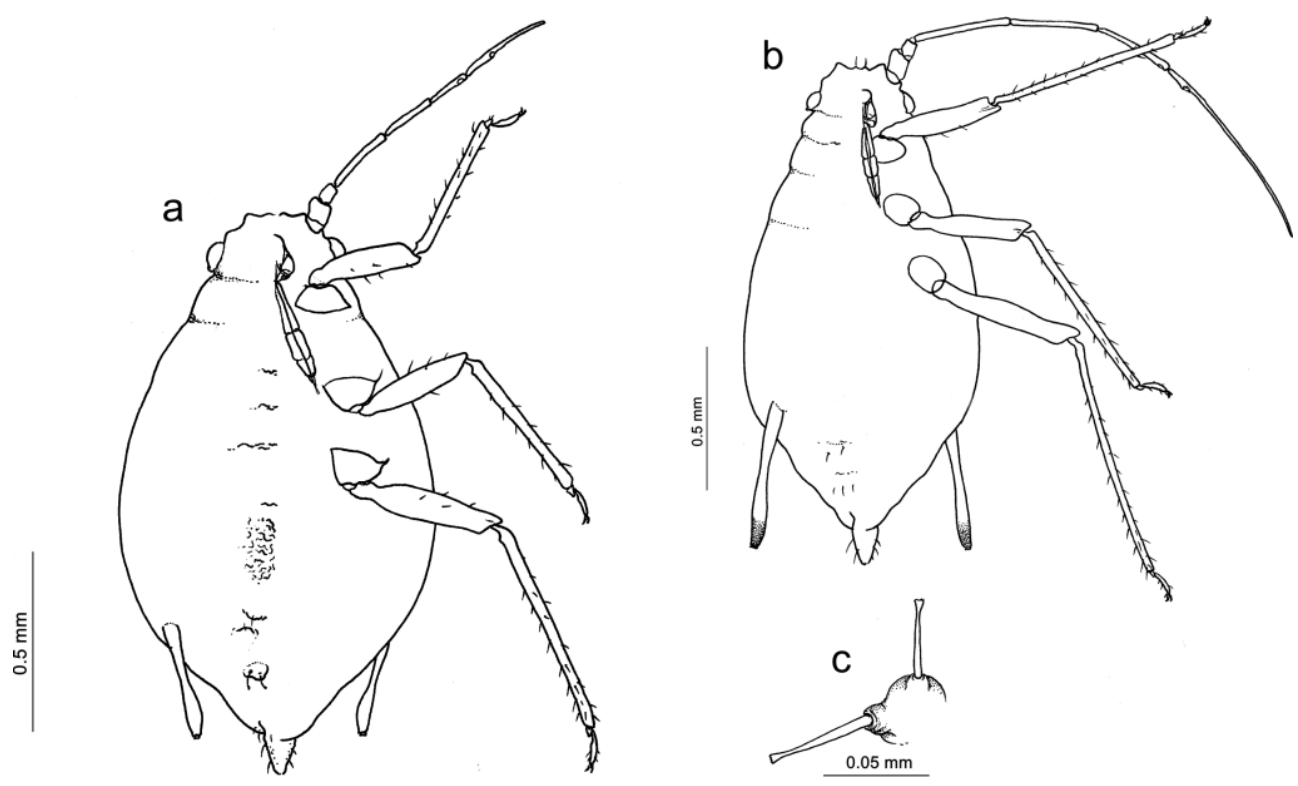

Fig. 1. Capitophorus wojciechowskii sp. n. - (a) fundatrix: general view; (b) apterous viviparous female: general view; (c) apterous viviparous female: spinal, fan-shaped setae.

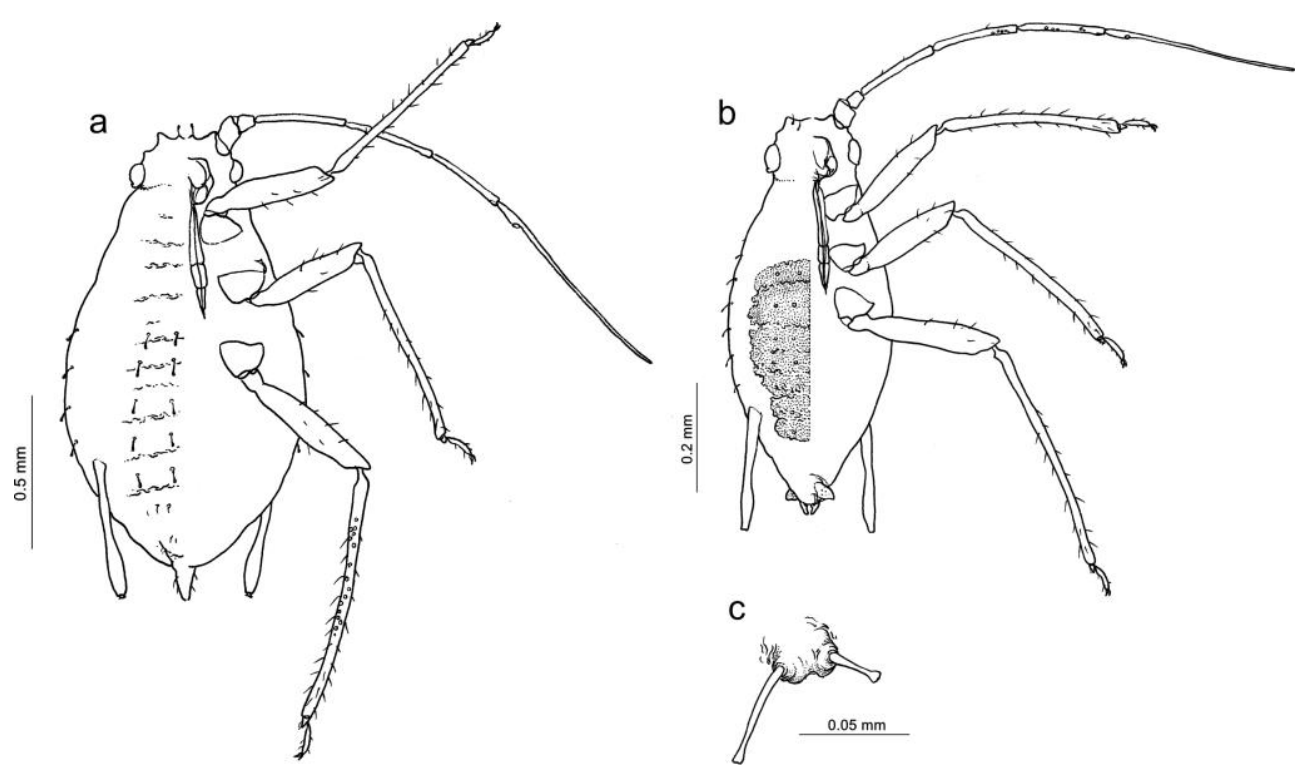

Fig. 2. Capitophorus wojciechowskii sp. n. - (a) oviparous female: general view; (b) male: general view; (c) male: spinal, capitate setae. 
Table 1. Measurements (in mm) of fundatrices $(n=4)$, apterous viviparous females $(n=3)$, oviparous females $(\mathrm{n}=10)$ and males $(\mathrm{n}=6)$ of Capitophorus wojciechowskii sp. $\mathrm{n}$. Fun - fundatrix, Avf - apterous viviparous female, Ofe - oviparous female, Mal - male.

\begin{tabular}{|l|c|c|c|c|}
\hline \multicolumn{1}{|c|}{ Character } & Fun & Avf & Ofe & Mal \\
\hline BL & $1.55-1.65$ & $1.50-1.85$ & $1.50-1.75$ & $1.40-1.50$ \\
\hline MW & $0.80-0.95$ & $0.70-0.87$ & $0.70-1.00$ & $0.62-0.68$ \\
\hline HW & $0.40-0.42$ & $0.36-0.40$ & $0.39-0.40$ & $0.38-0.43$ \\
\hline ANT & $0.81-0.90$ & $1.74-1.89$ & $1.66-1.71$ & $1.69-1.80$ \\
\hline ANT III & $0.20-0.22$ & $0.35-0.36$ & $0.30-0.34$ & $0.31-0.35$ \\
\hline ANT IV & $0.14-0.15$ & $0.25-0.32$ & $0.28-0.30$ & $0.30-0.34$ \\
\hline ANT V & $0.11-0.14$ & $0.25-0.29$ & $0.20-0.26$ & $0.26-0.27$ \\
\hline ANT VI & $0.27-0.31$ & $0.73-0.79$ & $0.68-0.70$ & $0.68-0.70$ \\
\hline BASE & $0.09-0.10$ & $0.08-0.09$ & $0.08-0.09$ & 0.09 \\
\hline PT & $0.17-0.22$ & $0.06-0.07$ & $0.60-0.62$ & $0.59-0.61$ \\
\hline ROSTR & $0.40-0.41$ & $0.30-0.35$ & $0.34-0.40$ & $0.35-0.40$ \\
\hline ARS & $0.11-0.12$ & $0.09-0.11$ & 0.11 & 0.12 \\
\hline III FEMUR & $0.35-0.38$ & $0.39-0.50$ & $0.44-0.50$ & $0.47-0.50$ \\
\hline III TIBIA & $0.64-0.67$ & $0.79-0.95$ & $0.85-0.91$ & $0.83-0.92$ \\
\hline HT I & 0.025 & 0.02 & 0.03 & $0.02-0.03$ \\
\hline HT II & $0.09-0.10$ & $0.09-0.10$ & $0.10-0.12$ & $0.11-0.15$ \\
\hline SIPHUNCULUS & $0.30-0.33$ & $0.47-0.50$ & $0.44-0.47$ & $0.42-0.44$ \\
\hline CAUDA & $0.15-0.16$ & $0.15-0.17$ & 0.15 & $0.12-0.13$ \\
\hline
\end{tabular}

\section{Description}

Fundatrix (Fig. 1a, Table 1)

Pigmentation. Colour of live specimens: unknown; mounted specimens: pale yellow.

Morphometric characters. Body egg-shaped. Head with large compound eyes and triommatidia. Frons concave with little developed diverging antennal tubercles. Dorsal side of head with 6 pairs of long and thick setae with fan-shaped apices; ventral side with 3-4 pairs of rather fine and blunt setae. Head setae 0.017-0.032 mm long, always longer than their maximum width. Antennae 6-segmented, slightly imbricated, with very short, blunt setae. ANT 0.49-0.58 x BL and 0.44-0.51 x HW. ANT I almost square-shaped. ANT III longer than ANT IV. ANT IV as long as or slightly longer than ANT V. ANT V always shorter than ANT VI. BASE with 1 small, rounded, ciliated primary rhinarium and 4-5 small accessory rhinaria closely adjoining each other with the major rhinarium. ANT I with 3-4 setae, ANT II with 2-3 setae, ANT III with 4-6 setae, ANT IV with 2-4 setae, ANT V with 2-3 setae; ANT VI with 3 basal, 3 apical and 1-2 setae on the basal part of PT. PT:BASE 1.70-2.44; other antennal ratios: ANT VI:ANT III 1.34-1.56; ANT V:ANT III 0.55-0.65; ANT IV:ANT III 0.68-0.75. 
ROSTR reaching hind coxae. ARS long with pointed apex with 2 primary and 2 accessory setae, $0.54-0.60 \times$ ANT III and 1.10-1.33 x HT II.

Abdominal tergites sclerotized, wrinkled, with rugose sculpture, covered by short setae with fan-shaped apices. Spinal setae duplicated, located on well-developed tubercles, 0.020-0.032 mm long. Pleural setae single on small tubercles, 0.017-0.020 mm long. Abdominal tergites I-V with marginal setae duplicated, 0.012-0.040 mm long; tergites I-VI with short submarginal setae. Siphunculi long and slender with distinct club-shaped swelling of distal part and surface wrinkled. Cauda tongue-shaped, with 8-12 fine and pointed setae.

Apterous viviparous female (Figs 1b-c, Table 1)

Pigmentation. Colour of live specimens: unknown; mounted specimens: pale yellow.

Morphometric characters. Body oval to spindle-shaped. Head with large compound eyes and triommatidia. Frons concave with little developed diverging antennal tubercles. Dorsal side of head with 6 pairs of long and thick setae with fan-shaped apices; ventral side with 3-4 pairs of rather fine and blunt setae. Head setae 0.02-0.05 mm long, always longer than their maximum width. Antennae 6-segmented, slightly imbricated, with very short, 0.010-0.012 mm long, blunt setae. ANT 1.02-1.16 x BL and 0.20-0.21 x HW. ANT I almost square-shaped. ANT III almost equal ANT IV. ANT IV as long as or slightly longer than ANT V. ANT V always shorter than ANT VI. BASE with 1 small, rounded, ciliated primary rhinarium and 4-5 small accessory rhinaria closely adjoining each other with the major rhinarium. ANT I with 4-5 setae, ANT II with 4 setae, ANT III with 8-11 setae, ANT IV with 6-9 setae, ANT V with 7-8 setae; ANT VI with 3 basal, 3 apical and 1-2 setae on the basal part of PT. PT:BASE 7.11-8.25; other antennal ratios: ANT VI:ANT III 2.02-2.25; ANT V:ANT III 0.72-0.81; ANT IV:ANT III 0.69-0.81.

ROSTR reaching hind coxae. ARS long with pointed apex with 2 primary and 2 accessory setae, $0.31 \times$ ANT III and 1.00-1.10 x HT II.

Legs long, setose. First tarsal segment with 3:3:3 setae. Empodial setae pointed.

Abdominal tergites membranous, without visible sculpture, covered by long, thick setae with fan-shaped apices. Spinal setae duplicated, on abdominal tergites I-IV located on small tubercles, on tergites V-VIII on well-developed tubercles, 0.020-0.055 mm long (Fig. 1c). Pleural setae single on small tubercles $0.020-0.032 \mathrm{~mm}$ long. Abdominal tergites I-V with marginal setae duplicated, $0.017-0.045 \mathrm{~mm}$ long; tergites I-VI with shorter submarginal setae. All setae on tergites VI-VIII 0.020-0.075 mm long. Siphunculi long and slender with distinct club-shaped swelling of distal part and surface, wrinkled. Subgenital plate oval. Cauda tongue-shaped, with 9-10 fine and pointed setae 
Oviparous female (Fig. 2a, Table 1)

Pigmentation. Colour of live specimens: unknown; mounted specimens: pale with slightly pigmented BASE, tips of tarsi and siphunculi.

Morphometric characters. Body pear-shaped. Head with large compound eyes and triommatidia. Frons convex with well-developed antennal tubercles and 4-6 capitate 0.25$0.40 \mathrm{~mm}$ long setae.

Antennae 6-segmented, imbricated, with very short, capitate setae. ANT 0.96-1.10 x BL and about $0.23 \times$ HW. ANT I square-shaped. ANT II rectangular. ANT III wider at base and apex. ANT IV as long as ANT III. ANT V with one large, oval, ciliated primary rhinarium at the apex. BASE with one major, ciliated rhinarium and 4-5 accessory rhinaria situated in the area of the major rhinarium, located very close to each other. ANT I with 2-3 setae, ANT II with 3 setae, ANT III with 4-6 setae, ANT IV with 4-5 setae, ANT V with 2-3 setae. PT with 3 basal and 3 apical setae. PT:BASE 6.66-7.29; other antennal ratios: ANT VI:ANT III 2.02-2.35, ANT V:ANT III 0.58-0.83, ANT IV:ANT III 0.82-1.00.

ROSTR reaching hind coxae. ARS long with pointed apex with 2 primary and 4 accessory setae, $0.32-0.38 \times$ ANT III and 0.93-1.09 x HT II.

Legs long, setose. Hind tibiae with 13-25 oval or circular pseudosensoria located along the whole length of tibiae. First tarsal segment with 3:3:3 setae. Empodial setae pointed.

Abdominal tergites sclerotized, wrinkled with rugose sculpture and fan-shaped setae. Spinal setae duplicated, located on small tubercles, shortest ones $0.02-0.025 \mathrm{~mm}$ long, longest ones $0.036-0.05 \mathrm{~mm}$ long. Pleural setae single on small tubercles $0.025-0.036 \mathrm{~mm}$ long. Abdominal tergites with marginal setae duplicated, 0.015-0.025 mm long; tergites I-VI with shorter submarginal setae. Siphunculi long and slender with distinct club-shaped swelling of distal part and surface, wrinkled. Subgenital plate oval. Cauda tongue-shaped, with 8-11 fine and pointed setae.

Apterous male (Figs 2b-c, Table 1)

Pigmentation. Colour of live specimens: unknown; mounted specimens: yellowish with slightly pigmented ANT IV-VI, dorsal sclerites and genitalia.

Morphometric characters. Body elongate. Head with large compound eyes and triommatidia. Frons convex with well-developed antennal tubercles and 3-4 capitate 0.20$0.25 \mathrm{~mm}$ long setae.

Antennae 6-segmented, imbricated, with very short, capitate setae. ANT 1.12-1.28 x BL and $0.22-0.23 \times \mathrm{HW}$. ANT I square-shaped. ANT II rectangular. ANT III wide at base as at apex, without secondary rhinaria. ANT IV as long as ANT III with 12-14 secondary rhinaria. ANT V with one large, oval, ciliated primary rhinarium at the apex and 12-17 secondary rhinaria. Secondary rhinaria small, rounded, not ciliated, distributed in a row. BASE with 1 major, ciliated rhinarium and 6 accessory rhinaria situated in the area of the 
major rhinarium, located very close to each other. ANT I with 3-4 setae, ANT II with 2-4 setae, ANT III with 4-6 setae, ANT IV with 2-4 setae, ANT V with 4-7 setae. PT with 2 basal and 3 apical setae. PT:BASE 6.42-6.55; other antennal ratios: ANT VI:ANT III 2.01-2.19, ANT V:ANT III 0.77-0.83, ANT IV:ANT III 0.96-0.97.

ROSTR reaching hind coxae. ARS long with pointed apex with 4 primary and 2 accessory setae, 0.34-0.40 x ANT III and about $1.04 \times$ HT II.

Legs long, setose. Tibiae with transverse rows of short spinules, long, erect pointed setae on distal part and five rastral spines. First tarsal segment with 3:3:3 setae. Empodial setae pointed.

Abdominal tergites I-VI fused, strongly sclerotized forming squarish patch additionally fused with metanotum, wrinkled, with rugose sculpture and capitate setae. Spinal setae duplicated, located on distinct tubercles, shortest ones $0.02-0.025 \mathrm{~mm}$ long, longest ones 0.036-0.05 mm long (Fig. 2c). Pleural setae single on small tubercles $0.02-0.03 \mathrm{~mm}$ long. Abdominal tergites with marginal setae duplicated, $0.018-0.043 \mathrm{~mm}$ long; tergites I-VI with shorter submarginal setae. Siphunculi long and slender with slight swelling of distal part and surface wrinkled. Cauda tongue-shaped, with 4-5 fine and pointed setae. Genitalia welldeveloped, strongly sclerotized with large, almost oval, setose, fused parameres and very short, hooked-shaped basal part of phallus.

\section{Distribution and host plants}

Known only from northern of Iran, Asara 850 m amsl, Gach-i-Sar 2000 m amsl, Karaj County, Alborz Province, and Fasham (Facham) 1900 m amsl, Sheminarat County, Teheran Province (MNHN). Host plants are Hippophae rhamnoides LINNAEUS, 1753 and Hippophae sp.

Key to Elaeagnaceae feeding apterous viviparous females of the genus Capitophorus (based on the key in BLACKMAN \& EASTOP 1994, 2015):

1. SIPH distinctly swollen on inner side subapically. 2.

- SIPH cylindrical or tapering, or only very slightly swollen (to less than 1.1 of minimum width) near apex.

2. ABD TERG 1-4 usually without submarginal setae, with 3 longitudinal rows of setae on each side; setae with fan-shaped apices and are usually longer than their maximum widths. SIPH less than $2.7 \times$ cauda.

Capitophorus hippophaes (WALKER, 1852).

- ABD TERG 1-4 usually with submarginal setae, with 4 more or less complete longitudinal rows of setae on each side; these setae are either long and capitate, or have mushroom- or balloon-shaped apices and are shorter than their maximum widths. SIPH more than $2.7 \times$ cauda. 
3. Setae on ABD TERG 1-4 capitate. Marginal setae single Capitophorus rhamnoides ZHANG, CHEN, ZHONG \& LI, 1999.

- Setae on ABD TERG 1-4 have mushroom- or balloon-shaped apices. Marginal setae usually duplicated.

4. Setae on ABD TERG 1-4 long, distinctly longer than their maximum widths. Cuticle in the marginal region smooth. External setae on hind tibiae long and with fanshaped apices. Capitophorus wojciechowskii sp. $\mathrm{n}$.

- Setae on ABD TERG 1-4 very short, with fan-shaped apices, shorter than their maximum widths. Cuticle in the marginal region rugose. External setae on hind tibiae short club-shaped.

5. ABD TERG 1-4 with pleural setae usually single. BL probably more than $1.4 \mathrm{~mm}$, and ANT PT/BASE probably more than 2.5 except in fundatrices. (The spring generations of this species on its primary host have not yet been recorded.

Capitophorus xanthii (OESTLUND, 1886).

- ABD TERG 1-4 with pleural setae mostly duplicate. BL less than $1.4 \mathrm{~mm}$, ANT PT/BASE less than 2.0. Capitophorus shepherdiae GILLETTE \& BRAGG, 1916.

6. ABD TERG 1-4 each with 6-8 setae (usually only one pair each of spinal, pleural and marginal setae). Capitophorus elaeagni (DEL GUERCIO, 1894).

- ABD TERG 1-4 each with 10-26 setae, due to duplication or multiplication of spinal, pleural and marginal setae on each tergite. 7.

7. SIPH short, tapering continuously from base to apex, less than $11 \times$ longer than width at midpoint.

.... Capitophorus himalayensis A.K. GHOSH, M.R. GHOSH \& RAYCHAUDHURI, 1971.

- SIPH attenuated, almost cylindrical except at base, or with slight subapical swelling; more than $12 \times$ width at midpoint. ... 8 .

8. Setae on ANT III all short, thin and inconspicuous, $0.3-0.5 \times$ basal diameter of segment. R IV+V 2.5-3.1 $\times$ HT II.

Capitophorus meghalayensis BASU \& RAYCHAUDHURI, 1976.

- ANT III with 1-5 forwardly-directed thick clavate setae like those on ANT II or a little shorter, 0.5-1.2 $\times$ longer than base of segment. R IV+V 1.5-2.6 $\times$ HT II. .... 9.

9. Thick capitate setae on ANT III all less than $0.8 \times$ basal diameter of segment. (R $\mathrm{IV}+\mathrm{V}$ 1.5-2.1 $\times$ HT II). Capitophorus similis VAN DER GOOT, 1915.

- Longest capitate setae on ANT III more than $0.8 \times$ basal diameter of segment. (R $\mathrm{IV}+\mathrm{V}$ 1.6-2.6 $\times$ HT II). 10.

10. ABD TERG 1-4 each with 18-26 capitate setae. R IV+V 2.1-2.6 × HT II Capitophorus pakansus HOTTES \& FRISON, 1931.

- ABD TERG 1-4 each with 12-19 capitate setae. R IV+V 1.6-2.1 × HT II. 


\section{DISCUSSION}

In the Elaeagnaceae-feeding Capitophorus there are two obvious groups of species based on the shape of the siphunculi: those with almost straight and those with evidently swollen siphunculi. C. wojciechowskii sp. n. belongs to the latter one but has an independent position in relation to most of them. In this group $C$. hippophaes is the most outside taxon because of the relatively short siphunculi and the lack of submarginal setae. Other species with swollen siphunculi differ from each other in the number of marginal setae and the new species, like $C$. xanthii and $C$. shepherdiae, has two marginal setae on the abdomen and differs in this character from $C$. rhamnoides. The type of chaetotaxy as well as the development of the dorsal cuticle (in apterous viviparous females) clearly distinguish C. xanthii and C. shepherdiae from C. wojciechowskii sp. n.

The new species is also illusively similar to $C$. archangielskii in the length and shape of the setae, but the almost straight siphunculi in $C$. archangielskii clearly distinguishes this species not only from $C$. wojciechowskii sp. n. but also from all other species in this group.

\section{REFERENCES}

Blackman R.L. 2010. Aphids - Aphidinae (Macrosiphini). Handbooks for the Identification of British Insects. Royal Entomological Society, London.

BlackMan R.L., EAStOP V.F. 1994. Aphids on the World's Trees. CAB International, Wallingford.

BLACKMAN R.L., EASTOP V.F. 2015. Aphids of the World's Plants: an Online Identification and Information Guide. Internet: http://www.aphidsonworldsplants.info/d_APHIDS_C.htm\#Capitophorus (Accessed 8 June 2015)

Received: 16 July 2015

Accepted: 27 August 2015 